\title{
Surgical Treatment of Achalasia: Current Status and Controversies
}

\author{
Farshad Abir Irvin Modlin Mark Kidd Robert Bell \\ Department of Surgery, Yale University School of Medicine, New Haven, Conn., USA
}

\section{Key Words}

Achalasia, esophageal $\cdot$ Heller myotomy $\cdot$ Balloon dilatation, endoscopic $\cdot$ Fundoplication

\begin{abstract}
Objective: To review the current management of achalasia, and the controversies regarding the different treatment options. Methods: A review of the literature was performed. The key words used were esophageal achalasia, Heller myotomy, endoscopic balloon dilatation, laparoscopic Heller myotomy, and fundoplication. Results: Patients who fail medical therapy (e.g. pharmacologic therapy, botulinum toxin, balloon dilatation) should be considered for surgical therapy for the management of achalasia. Currently, numerous surgical procedures exist for the treatment of achalasia (transabdominal cardiomyotomy, thoracoscopic or open transthoracic cardiomyotomy, and laparoscopic Heller myotomy with an antireflux procedure). Conclusions: Laparoscopic Heller myotomy is generally accepted as the operative procedure of choice for achalasia. However, controversy exists as to whether a concomitant antireflux procedure is necessary, and if so, what type should be performed. Given the deleterious effects of postoperative reflux, and the facility of including an antireflux procedure at the time of the myotomy, there is merit in undertaking an antireflux procedure at the time of the laparoscopic Heller myotomy.
\end{abstract}

\section{Historical Background}

Although considered a more recent disease uncovered by sophisticated 20th century manometry, it is noteworthy that more than 300 years ago, Thomas Willis (16211675) described an individual with an inability to swallow. Desperate and starving, the patient sought the advice of Willis, who concluded that the problem was due to a lower esophageal narrowing and the presence of a massively dilated esophagus. Not satisfied with this prescient diagnosis, Willis thereupon devised a novel device to alleviate the problem and constructed one of the first dilators, or probangs. This consisted of a piece of whalebone with a sponge attached to its distal end, which could be repeatedly inserted through the mouth and down the esophagus to achieve dilatation [1]. Suffice it to say that the patient lived for many years and is considered to represent the first successful treatment of achalasia.

The etiology of the disorder that constituted an unrelaxed lower esophageal sphincter (LES) remained unclear for centuries and was generically referred to as "cardiospasm'. In 1927, Sir Arthur Hurst who had become acquainted with the use of barium to study gastrointestinal motility noted that the LES failed to relax normally in such patients and coined the term achalasia [2].

\section{KARGER \\ Fax + 41613061234 \\ E-Mail karger@karger.ch \\ www. karger.com \\ (c) 2004 S. Karger AG, Basel \\ 0253-4886/04/0213-0165\$21.00/0 \\ Accessible online at: \\ www. karger.com/dsu}

\author{
Dr. Robert Bell \\ Yale University School of Medicine \\ Department of Surgery, TMC, 333 Cedar Street \\ New Haven, CT 06520-8062 (USA)
}

Tel. +1 203764 9060, E-Mail robert.bell@yale.edu 


\section{Introduction}

Achalasia is rare, with an estimated annual incidence of 1 per 100,000 persons in westernized countries [3]. The condition occurs at any age, exhibits no gender predilection and has been described from infancy to the ninth decade, with the majority of patients presenting between the ages of 20 and 40 years. Overall it encompasses a primary esophageal motility disorder characterized by the inability of the LES to relax and failure of esophageal body peristalsis and appears to have no associated synchronous systemic effects. In the majority of cases in North America, the etiology of achalasia remains unknown although in South America many patients have infestation by Trypanosoma cruzi as an underlying pathogenesis.

The most common histological finding in patients with primary achalasia is a decrease or loss of myenteric ganglionic cells. Despite considerable investigation, the cause of the ganglion cell degeneration is unknown, although an association with class II HLA antigen DQw1, implicating an autoimmune mechanism, has been described [4]. Numerous hypotheses for the etiology of achalasia have been proposed, suggesting possible infectious agents such as varicella zoster and degenerative neurologic disorders, but to date there appears to be no specific entity identifiable as the inciting agent in the vast majority of patients. The pathophysiology of the process represents a selective loss of inhibitory nerves that results in unopposed stimulation of the smooth muscle fibers of the LES [4].

Chagas' disease, an infectious disease caused by the protozoa T. cruzi (found in Central and South America), may lead to a condition similar to achalasia. In the past, Chagas' disease affected 1 in 8 Brazilians, with $5 \%$ of these developing esophageal motility problems [5]. However, for unknown reasons, the incidence of this disease has decreased in the last 20 years, although it has been proposed that this possibly reflects the impact of public health programs.

\section{Clinical Presentation}

Achalasia may present at either an early or late phase in the disease process and reflects the degree to which ingestion of food is impaired. Thus the consequences of achalasia may be subtle early in its course, becoming more severe with disease progression. As a result, patients may present with a wide variety of symptoms, depending on both their sensitivity to the swallowing difficulty or the stage of disease at the time of diagnosis. Most complaints are secondary to the progressive obstruction to the passage of solids and liquids at the gastroesophageal (GE) junction. The main symptoms are dysphagia and chest pain though in the late stages halitosis and even reflux of swallowed material may occur. Other common symptoms include heartburn, weight loss, aspiration (wheezing, coughing, choking, pneumonia), tracheal deviation/obstruction, and hematemesis (secondary to esophageal ulcerations). As a result of the slow and often insidious nature of the process, the diagnosis of achalasia is often delayed. In addition, the symptoms often mimic gastroesophageal reflux disease (GERD), angina, or acute myocardial infarction, culminating in further delay while alternative diagnoses are pursued.

\section{Clinical Evaluation}

There are a wide variety of clinical features that suggest that a diagnosis of achalasia should be considered. It is noteworthy that the particular stage of the disease process plays a large role in determining the specific features apparent in a particular patient. Non-specific findings on chest X-ray may include mediastinal widening, presence of an air-fluid level in the mid-esophagus, absence of a gastric air bubble, and abnormal pulmonary markings due to chronic aspiration. A barium swallow may reveal a dilated esophageal body with smooth tapering to a 'bird's beak' at the level of the LES (fig. 1). It is of importance to recognize that in the early phases of the disease process, little or no dilatation may be evident on barium swallow, although there often some evidence of 'spasm' or tertiary contractions. As the disease progresses, there is continued dilatation of the esophagus until ultimately it evolves into a dilated, tortuous and even sigmoid appearing tubal structure. In some individuals, pulsion diverticula may also develop and represent the final stages of a weakened esophageal wall in the presence of increased intraluminal pressure consequent upon the failure of the LES relaxation. Such diverticula, particularly at the lower end, constitute a hazard to endoscopy or dilatation and their presence should engender caution.

Flexible upper endoscopy should be performed routinely to exclude any other benign or malignant diseases that may mimic achalasia. Although extremely rare, malignancy (small cell carcinoma of the esophagus) may occur in patients with long-standing achalasia [6]. A clear view of the LES area is important but may on occasion be difficult to obtain because of retained food particles. The 
classic endoscopic picture is that of a dilated, patulous esophageal body that may have extensive mucosal friability and ulcerations due to stasis of food and secretions [7]. Although in most circumstances the endoscope enters the stomach with little difficulty there may be some moderate resistance during passage through the LES. If substantial difficulty is encountered during this maneuver, the possibility of a peptic or malignant stricture should be considered. In patients who have had previous dilatations with subsequent fibrosis, increased resistance may be noted on passage of the LES. Once the scope is introduced into the stomach, a retroflexed view of the GE junction should be obtained in order to ensure that all mucosal abnormalities are identified and biopsied.

Although a visual evaluation of the esophagus and stomach is helpful and may rule out any concomitant conditions, manometry is the gold standard for establishing the diagnosis of achalasia. In particular, it is important in differentiating achalasia from other esophageal motility disorders such as diffuse esophageal spasm and scleroderma. Nevertheless, manometry may not reliably exclude some of the more common causes of 'pseudo-achalasia', such as cancer or peptic stricture, and equivocal pressure and motility patterns require careful consideration to confirm the certain diagnosis of achalasia. Endoscopic ultrasonographic evaluation of patients with achalasia has been discussed but support is equivocal since imaging artifacts may lead to misinterpretation [8]. The cardinal manometric requirements for the diagnosis of achalasia include absent peristalsis of the distal smooth muscle segment of the esophagus, increased LES pressure, and failure of the LES to relax upon swallowing. Although elevated LES pressures $(>35 \mathrm{~mm} \mathrm{Hg}$ ) may be evident, the most classic and specific manometric finding that validates the diagnosis of achalasia is incomplete sphincter relaxation, which occurs in more than $80 \%$ of patients [9]. An average LES relaxation of $35.3 \pm 1.8 \%$ for achalasia patients compares with $95.4 \pm 1.6 \%$ in controls [10]. In some cases, the actual inability to pass the manometric device into the stomach makes the assessment of the LES pressure imprecise.

\section{Medical Therapy}

There is no specific therapy available for the management of the underlying disease process since the pathogenesis of the neuropathology responsible for the impaired esophageal peristalsis and LES relaxation is unknown. As a result, therapeutic strategies have for the

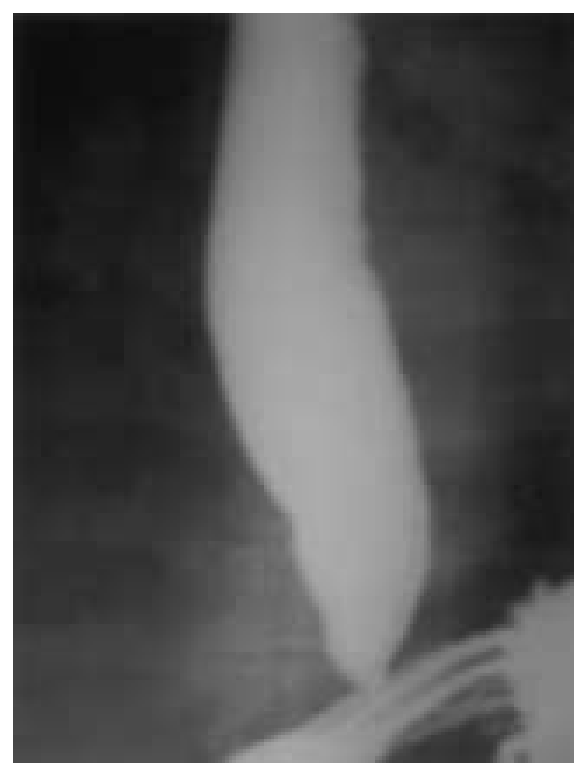

Fig. 1. A barium swallow demonstrating the bird-beak appearance of the lower esophagus, dilatation of the esophagus, and stasis of the barium in the esophagus.

most part been directed at seeking to reduce the LES pressure or augment the passage of food and fluid through it. Gravity, alone or in combination with various medical therapies, facilitates esophageal emptying and reduces the symptoms associated with esophageal retention. Thus individuals with achalasia, whether consciously or subconsciously, tend to remain upright after eating and drink water to promote passage of food through LES.

\section{Pharmacological Therapy}

The likelihood of successful pharmacotherapy in patients with achalasia is low given the fact that the neurohormonal regulation of LES function is ill understood. Indeed, no specific smooth muscle agonist or antagonist targeting the LES currently exists. Nevertheless, over several decades a number of pharmacologic agents have been utilized for the treatment of achalasia with moderate success. All share the common mechanism of lowering LES tone, but they do not improve LES relaxation in response to a swallow. In addition, many of these drugs have collateral adverse effects that outweigh what little putative benefit they have on esophageal emptying. In recent times, calcium channel blockers and long-acting nitrates are the two most common medications that have been used for 
treating achalasia [11]. Other less commonly employed agents that have been utilized in the past include anticholinergics (atropine, dicyclomine, cimetropium, and bromide), $[\beta]$-adrenergic agonists (terbutaline), and theophylline. The common difficulty with such medications is that they relax smooth muscle, which leads to a lower resting LES pressure, but do not improve LES relaxation or augment esophageal peristalsis. An alternative strategy has been the use of calcium channel blocker of which is nifedipine is regarded as the most effective; overall however, this class of agents has been reported to decrease LES pressure by $13-49 \%$ and improve symptoms by $0-75 \%$ [11]. The long-acting nitrates, such as isosorbide dinitrate (Isordil, Wyeth-Ayerst, Philadelphia, Pa., USA), are effective in decreasing LES pressure by 30-65\% when administered sublingually or orally, symptoms improve in 53$87 \%$ of patients with achalasia [11]. A study that compared sublingual nifedipine to sublingual isosorbide dinitrate noted that both agents decreased LES pressure but the effect was slightly, but not significantly, better with nitrates (65\%) compared with nifedipine (49\%) [12].

Unfortunately the clinical response to pharmacological agents appears to be short acting and includes substantial adverse events such as headache, hypotension, and pedal edema. Such difficulties are accentuated by the fact that the agents for the most part fail to provide complete relief of symptoms. Although a randomized, placebo-controlled study [13] of nifedipine demonstrated significant reduction in both LES pressures and symptoms, dysphagia was still evident in the treated group. Given these limitations, the use of nifedipine or isosorbide dinitrate should be reserved for patients who are (a) very early in their disease with a non-dilated esophagus; (b) not candidates for either pneumatic dilatation or surgery; (c) who refuse invasive therapy, or (d) have failed botulinum toxin injections.

\section{Botulinum Toxin (Botox)}

Given the relatively modest efficacy of systemic pharmacotherapy therapy, attempts have been made to address the sphincter directly. Botulinum toxin, which inhibits the release of acetylcholine from the presynaptic nerve endings, is a relatively novel agent that has recently been investigated. It has been proposed that direct intrasphincteric injection might be of some utility in decreasing LES pressure. Indeed, endoscopic intrasphincteric injection of botulinum toxin has been shown to significantly ameliorate the symptoms of achalasia and the early cumulative data indicate that botulinum toxin initially relieves symptoms in about $85 \%$ of patients [14]. Unfortunately the intervention is relatively short lived in its response and symptom recurrence occurs in more than $50 \%$ of patients by 6 months. More recent studies indicate that Botox injection is less efficacious than balloon dilatation in treating patients with achalasia $[15,16]$.

\section{Balloon Dilatation}

It is a sad reflection on the lack of progress that has been made in this area to date that the simplistic technique of forceful dilatation of the distal esophagus is still considered the most effective non-surgical treatment for achalasia. The objective of this therapy is to produce a controlled tear of the LES, in essence rendering it incompetent, resulting in relief of distal esophageal obstruction and symptomatic improvement. It is of course mandatory to achieve an effective tear yet refrain from perforating the esophagus. In the past, fixed-diameter dilators and a variety of mercury-weighted bougies, hydrostatic dilators, and pneumatic dilators have all been utilized with varying degrees of success. At this time, the most safe and effective means of dilatation is achieved using controlled pneumatic pressure devices. With this technique, a balloon is placed across the LES under direct endoscopic visualization. The balloon is inflated for $1-3 \mathrm{~min}$ to a pressure of $300 \mathrm{~mm} \mathrm{Hg}$ (10-12 psi). To obtain an acceptable therapeutic effect, dilatation to a diameter of at least $3 \mathrm{~cm}$ must be performed, and the procedure should lower the resting LES pressure to $<10 \mathrm{~mm} \mathrm{Hg}$. The immediate success rate of this procedure is $55-70 \%$ with a single dilatation, but can be increased to $90 \%$ with multiple dilatations. However, $15-48 \%$ of patients need repeat dilatations, with a mean of 1.2-1.6 dilatations per patient. The best results can be obtained by using incrementally larger balloon sizes during successive dilatations.

After pneumatic dilatation, good to excellent symptomatic relief has been reported in $67-93 \%$ of patients after a mean follow-up of 0.3-4 years [17]. Unfortunately, the data for the long-term results are less effective. Anselmino et al. [18] found that dysphagia was alleviated in only 12 of 31 patients (39\%) who were treated by pneumatic dilatation after a mean follow-up of 55 months. Eckard et al. [19] demonstrated that $60 \%$ of patients were symptom-free at the 1-year follow-up, but after 5 years more than half of these individuals had recurrence of their symptoms. Patients who respond to dilatation usually can be treated successfully with a second attempt, but patients who do not respond to a first dilatation are likely to fail additional dilatations. Parkman et al. [20] showed that $40 \%$ of patients treated by a single dilatation require a second dilatation after 5 years. Patients who have undergone a second or third dilatation require subsequent dila- 
tations in 40 and $75 \%$ of cases respectively. Interestingly, symptomatic improvement may not always correlate with manometric or radiographic findings. Neither a low LES pressure, nor improvement of radionuclide emptying studies, nor a decrease in esophageal diameter, as measured by esophagram, accurately predict symptomatic improvement.

The dilatation procedure can usually be performed on an outpatient basis but the patient should be observed for a minimum of $6 \mathrm{~h}$ prior to discharge since most complications, such as bleeding, intramural hematoma, and perforation manifest within this time frame. Any complaint of chest pain or discomfort should be regarded with concern and prompt evaluation. Esophageal perforation occurs predominately above the cardia on the left posterior lateral side of the esophagus. This part of the esophagus has no external 'bolstering' by the posterior vertebra and the right posterior aorta) and is most likely area to distend and tear (Boerhaave's triangle). Esophageal perforation rates after pneumatic dilatation vary widely from 0 to $15 \%$, and are to a large extent operator-dependent although a prolonged duration of the disease and an increased number of previous dilatations increase the likelihood [19, 20].

\section{Surgical Therapy}

Given the relatively modest effects of medical therapy and the shortcomings of blind dilatation, alternative strategies were considered for the management of this chronic but debilitating disease of achalasia. A natural surgical solution seemed to be the destruction of the 'spastic' sphincter. Thus, as early as 1913, Ernest Heller (18771964) reported successful management of the condition by undertaking a cardiomyotomy for achalasia (fig. 2) [21]. His original technique used parallel (anterior and posterior) myotomies extending for $8 \mathrm{~cm}$ or more along the distal esophagus and proximal gastric cardia. Although this technique was successful in ameliorating the symptoms of achalasia, excessive GE reflux often resulted. In 1918, De Brune Groenveldt [22] and Zaaijer [23], recognizing the somewhat excessive nature of this procedure, described a single, anterior esophagocardiomyotomy that is still referred to as a Heller myotomy in the vernacular, and has remained the operative procedure of choice almost 85 years later.

Four groups of patients have been defined in whom a surgical approach to cardiomyotomy for achalasia is considered appropriate. The first group consists of younger

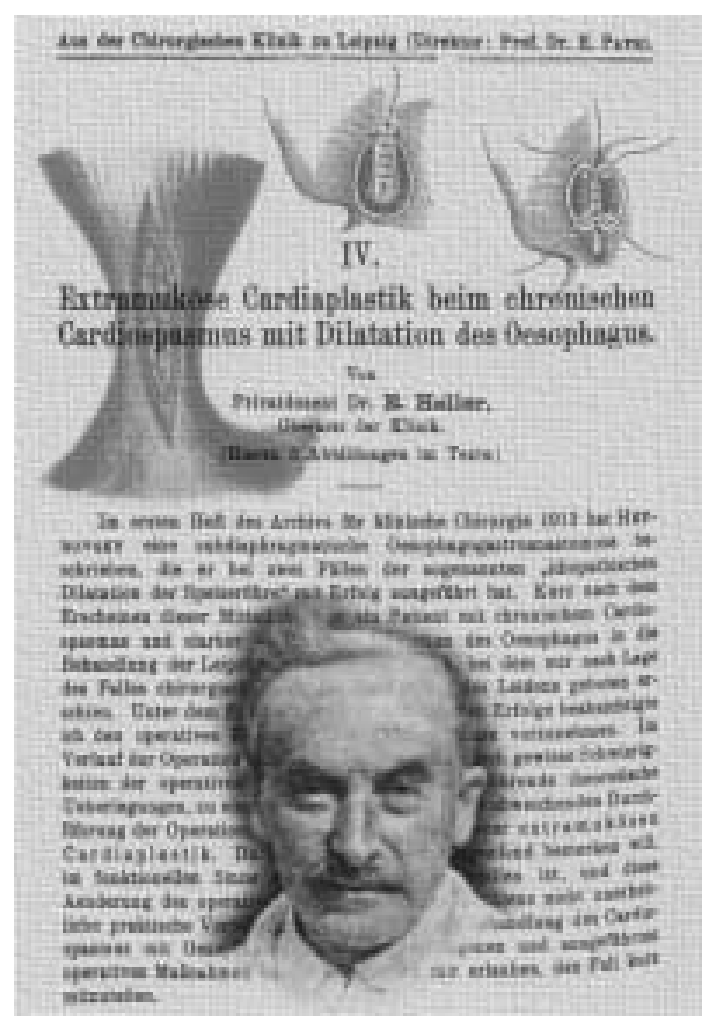

Fig. 2. Ernst Heller (1877-1964) (bottom) published a report in 1914 (background) on the use of extramucosal esophagomyotomy for the treatment of achalasia of the esophagus. Top left is his original drawing of the operation, compared to the other anastomotic cardioplasties developed in Germany in the first half of the 20th century (top right). Heller made a complete division of the longitudinal and circular muscle fibers and did not extend the myotomy into the stomach.

patients ( $<40$ years) in whom lifelong dilatation may be predicted, since pneumatic dilatation is effective in only $50-70 \%$ of patients. A factor in this decision is the fact that the perforation rate of $2-7 \%$ is cumulative and the disease does not spontaneously remit. The second group includes patients who have been treated repeatedly with pneumatic dilatation or Botox injections, but have persistent or recurrent symptoms. Although some physicians (mostly surgeons) would primarily advocate surgery, other practitioners are guided by the number of non-operative interventions, whether pneumatic dilatation or Botox injection, that have been attempted prior to considering a patient for surgical intervention. The third group consists of patients who are considered high risk to undergo pneumatic dilatation and includes patients with previous surgery at the GE junction, esophageal diverticula, or distorted lower esophageal anatomy secondary to a tortuous 
Table 1. Transabdominal Heller myotomy ( $\mathrm{n}=18$ studies; $1975-2002$ )

\begin{tabular}{|c|c|c|c|c|c|c|c|c|}
\hline $\begin{array}{l}\text { Group } \\
\text { (first author) }\end{array}$ & Year & $\mathrm{n}$ & Design & $\begin{array}{l}\text { Antireflux } \\
\text { procedure }\end{array}$ & $\begin{array}{l}\text { Symptom } \\
\text { improve- } \\
\text { ment, \% }\end{array}$ & $\begin{array}{l}\mathrm{F} / \mathrm{U} \\
\text { years }\end{array}$ & $\begin{array}{l}\% \text { compl } \\
\text { GERD }\end{array}$ & $\begin{array}{l}\% \text { compl } \\
\text { mortality }\end{array}$ \\
\hline Csendes [30] & 1975 & 20 & $\mathrm{P}$ & No & 95 & 2.8 & 0 & 0 \\
\hline Black [31] & 1976 & 108 & $\mathrm{R}$ & Yes & 66 & 4.0 & 19 & 0 \\
\hline Kessler [32] & 1980 & 49 & $\mathrm{R}$ & Yes & 90 & - & 0 & 2 \\
\hline Veiga-Fernandes [33] & 1981 & 15 & $\mathrm{P}$ & Yes & 100 & - & 0 & 0 \\
\hline Csendes [34] & 1988 & 100 & $\mathrm{P}$ & Yes & 92 & 6.8 & 19 & 0 \\
\hline Gonzalez [35] & 1988 & 1,856 & $\mathrm{R}$ & No & 82 & - & 26 & 0 \\
\hline Sauer [36] & 1989 & 8 & $\mathrm{R}$ & - & 88 & 4.0 & - & 13 \\
\hline Isolauri [37] & 1990 & 12 & $\mathrm{P}$ & Yes & 91 & - & 8 & 0 \\
\hline Makela [38] & 1991 & 13 & $\mathrm{R}$ & Yes & 69 & 2.0 & 15 & 0 \\
\hline Jaakkola [39] & 1991 & 26 & $\mathrm{R}$ & No & 48 & 8.75 & - & - \\
\hline Bonavina [40] & 1992 & 206 & $\mathrm{R}$ & Yes & 94 & 5.5 & 9 & 0 \\
\hline Picciocchi [41] & 1993 & 21 & $\mathrm{R}$ & Yes & 81 & 9.5 & 25 & 0 \\
\hline Kumar [42] & 1994 & 10 & $\mathrm{R}$ & No & 90 & 1.4 & 23 & 0 \\
\hline Mattioli [43] & 1996 & 62 & $\mathrm{R}$ & No & 48 & 16.0 & 10 & 0 \\
\hline Pandolfo [44] & 1996 & 11 & $\mathrm{P}$ & No & 88 & 2.0 & 22 & 0.2 \\
\hline Del Genio [45] & 1997 & 87 & $\mathrm{P}$ & Yes & 100 & 4.1 & - & - \\
\hline Jordan $[46]$ & 2001 & 25 & $\mathrm{P}$ & Yes & 84 & 10.0 & 4 & 4 \\
\hline Junginger [47] & 2002 & 51 & $\mathrm{P}$ & Yes & 96 & 7.3 & 3.9 & 0 \\
\hline Totals & & 2,680 & & & $83 \pm 15$ & $6 \pm 3.9$ & $12.3 \pm 9$ & $1.2 \pm 3$ \\
\hline
\end{tabular}

distal esophagus. The fourth group is constituted by those individuals who prefer surgery over pneumatic dilatation due to its lower risk of perforation, better long-term outcome, and a decreased likelihood of re-intervention. As might be predicted given the uncertain pathogenesis of the disease, numerous surgical techniques, each with its group of proponents, have been used for the treatment of achalasia. These different techniques will be discussed below.

Transabdominal Cardiomyotomy. Transabdominal cardiomyotomy is now the most commonly performed procedure for the treatment of achalasia. The results from 18 published studies (1975-2002) using the abdominal approach are summarized in table 1. Based upon an assessment of these 2,680 patients, good to excellent symptom improvement may be predicted in greater than $83 \%$ of patients using this technique and can be attained with a low operative mortality (1.2\%). Objective analysis indicates that the mean LES pressure is decreased by $74 \%$ with the abdominal approach. The most significant early complication of myotomy is perforation of the esophageal mucosa at the time of surgery. When suspected, it is mandatory to rule out a perforation intraoperatively (endo- scopic inspection and insufflation) and repair any mucosal defect. The predominant late complication of a Heller's myotomy is the advent of GERD consequent upon the extensive damage to the LES. The cumulative rate of reflux disease is at least $12 \%$ utilizing the abdominal approach although such numbers are not particularly robust given the wide variety of criteria (symptomatic heartburn, $\mathrm{pH}$ testing, endoscopic) utilized to define the diagnosis of GERD. A further problem, albeit less common, is the late development of peptic strictures and Barrett's esophagus after myotomy. Although the precise mechanism is unclear the high incidence of GERD probably reflects a combination of LES damage, and damage to the anterior vagal component of the nerve supply to the gastric pacemaker. Interference with transient lower esophageal relaxation and the mechanical function of the cardia may also be factors. As a consequence of this predictably high adverse event (GERD), it is considered prudent and reasonable to combine the myotomy procedure with an antireflux procedure, preferentially a Dor or Toupet (partial) fundoplication.

Transthoracic Open Approach. Given the fact that the esophagus traverses both the thorax and the abdomen, 
Table 2. Transthoracic approach to myotomy ( $\mathrm{n}=21$ studies; $1976-2001)$

\begin{tabular}{llrllllll}
\hline $\begin{array}{l}\text { Group } \\
\text { (first author) }\end{array}$ & Year & $\mathrm{n}$ & Design & $\begin{array}{l}\text { Antireflux } \\
\text { procedure }\end{array}$ & $\begin{array}{l}\text { \% symptom } \\
\text { improve- } \\
\text { ment }\end{array}$ & years & $\begin{array}{l}\text { \% compl } \\
\text { GERD }\end{array}$ & $\begin{array}{l}\text { compl } \\
\text { mortality }\end{array}$ \\
\hline Mansour [48] & & & & & & & \\
Okike [49] & 1976 & 25 & $\mathrm{R}$ & No & - & - & 36 & 0 \\
Jara [50] & 1979 & 468 & $\mathrm{R}$ & No & 85 & 6.4 & 3 & 0.2 \\
Bjork [51] & 1979 & 121 & $\mathrm{R}$ & No & 80 & 7.1 & 52 & 0 \\
Ellis [52] & 1982 & 52 & $\mathrm{P}$ & No & 85 & - & - & - \\
Murray [53] & 1984 & 103 & $\mathrm{R}$ & No & 76 & 6.8 & 4 & 0 \\
Pai [54] & 1984 & 14 & $\mathrm{P}$ & Yes & 93 & 3.9 & 0 & 0 \\
Goulbourne [55] & 1984 & 16 & $\mathrm{P}$ & No & 94 & 5.1 & - & 0 \\
Little [56] & 1985 & 65 & $\mathrm{R}$ & No & 80 & 8.3 & 5 & 0 \\
Stipa [57] & 1988 & 34 & $\mathrm{R}$ & Yes & 88 & 4.8 & 0 & 0 \\
Shoenut [58] & 1990 & 43 & $\mathrm{R}$ & Yes & 87 & - & 2 & 0 \\
Jaakkola [39] & 1990 & 15 & $\mathrm{P}$ & No & - & 0.5 & - & - \\
Ellis [59] & 1991 & 34 & $\mathrm{R}$ & No & 94 & 14.3 & - & - \\
Abid [60] & 1993 & 179 & $\mathrm{R}$ & No & 80 & 9 & 5 & 0 \\
Malthaner [61] & 1994 & 9 & $\mathrm{R}$ & No & 89 & 1.5 & - & - \\
Ferguson[62] & 1994 & 22 & $\mathrm{R}$ & Yes & 95 & 14 & 18 & - \\
Anselmino [18] & 1996 & 60 & $\mathrm{R}$ & No & 88 & - & - & - \\
Maher [63] & 1997 & 22 & $\mathrm{R}$ & Yes & 91 & 3.8 & 10 & - \\
Shai [64] & 1997 & 21 & $\mathrm{P}$ & No & 80 & 1.9 & - & 0 \\
Rea [65] & 1999 & 51 & $\mathrm{P}$ & No & 81 & 7.4 & 6 & 0 \\
Jordan [66] & 1999 & 9 & $\mathrm{P}$ & No & 89 & - & 0 & 0 \\
\hline Totals & 2001 & 16 & $\mathrm{P}$ & Yes & 85 & 10.0 & 0 & 0 \\
\hline & & 1,379 & & & $86 \pm 5$ & $6.6 \pm 4$ & $10 \pm 15$ & $0.01 \pm 0.05$ \\
\hline
\end{tabular}

$\mathrm{P}=$ Prospective $; \mathrm{R}=$ retrospective $; \mathrm{F} / \mathrm{U}=$ follow- $\mathrm{up}, \mathrm{compl}=$ complications; mean $\pm \mathrm{SDEV}$.

there has been some discussion as to whether the management of achalasia should be regarded as the province of thoracic or gastrointestinal surgeons. As a result there are proponents of an extra abdominal technique for dealing with achalasia addressing the problem by utilizing a left thoracotomy technique for myotomy. Surgeons who use this approach have argued that this technique minimizes the disruption of the normal antireflux mechanism and is therefore less likely to culminate in the later development of GERD (an argument supported more by emotion than fact). After mobilization of the inferior pulmonary ligament and protection of the vagus nerves, an esophageal myotomy is carried superiorly to the inferior pulmonary vein and inferiorly, $5 \mathrm{~mm}$ onto the gastric fundus. In order to facilitate the latter procedure it is often necessary to mobilize the GE junction cephalad and remove the gastric fat pad to provide adequate visibility and access.

Several prospective and retrospective clinical trials have studied the effectiveness and complication rates of the transthoracic approach. Overall good to excellent results were reported in $86 \%$ of patients undergoing a transthoracic procedure with the mean LES pressure being reduced by $79 \%$ and an operative mortality of $0.01 \%$ (table 2). Despite the proposed protective effect of this procedure, the cumulative rates of GERD were $10 \%$. The cumulative results comparing the open abdominal vs. thoracic approach demonstrate no significant differences in these approaches except that mortality was $\sim 100$ times higher in the transabdominal group ( $\mathrm{p}=\mathrm{NS}, \mathrm{t}$ test).

Thoracoscopic Approach. Given the advantages of minimally invasive surgery the consideration of approaching the esophagus using this technique has become an attractive alternative over the last decade. The general experience with thoracoscopic myotomy demonstrates good to excellent symptom improvement in $76 \%$ of 204 treated patients (table 3). Unfortunately, the unacceptably high rate of persistent dysphagia (up to $26 \%$ ) and secondary GERD (35\%) has led to some diminution of enthusiasm for this procedure. For the most part the limitations of the procedure reflect the technical difficulties in 
Table 3. Thoracoscopic approach ( $\mathrm{n}=10$ studies; 1993-2003)

\begin{tabular}{lccllll}
\hline Group (first author) & $\mathrm{n}$ & Year & Design & $\begin{array}{l}\text { \% symptom } \\
\text { improvement }\end{array}$ & $\begin{array}{l}\text { F/U } \\
\text { years }\end{array}$ & $\begin{array}{l}\% \text { compl } \\
\text { GERD }\end{array}$ \\
\hline Pelligrini [67] & 30 & 1993 & $\mathrm{P}$ & 87 & 1 & 60 \\
Patti [68] & 30 & 1995 & $\mathrm{P}$ & 87 & - & - \\
Cade [69] & 12 & 1996 & $\mathrm{P}$ & 92 & 0.3 & 18 \\
Raiser [70] & 10 & 1996 & $\mathrm{P}$ & 62 & 1.2 & 57 \\
Nguyen [71] & 15 & 1998 & $\mathrm{P}$ & 66 & 1.6 & 27 \\
Patti [72] & 35 & 1999 & $\mathrm{R}$ & 85 & - & 60 \\
Cade [73] & 17 & 2000 & $\mathrm{P}$ & 82 & 2 & 35 \\
Codispoti [24] & 25 & 2003 & $\mathrm{P}$ & 54 & 5.4 & 24 \\
Ramacciato [74] & 16 & 2003 & $\mathrm{P}$ & 62 & - & 31 \\
Lee [25] & 14 & 2003 & $\mathrm{P}$ & 86 & 4.7 & 7 \\
\hline Totals & 204 & & & $76 \pm 13$ & $2.3 \pm 1.8$ & $35 \pm 18$ \\
\hline
\end{tabular}

$\mathrm{P}=$ Prospective; $\mathrm{R}=$ retrospective $; \mathrm{F} / \mathrm{U}=$ follow-up; compl = complications; mean \pm SDEV. performing the myotomy in the perpendicular plane to the esophagus, as well as judging the appropriate extent of the myotomy onto the stomach. Critics of the operation have also cited the greater postoperative pain and the longer hospital stay after a thoracoscopic method compared with the laparoscopic operation as substantial disadvantages and the body of opinion has tended to favor the abdominal approach since it provides the opportunity to not only undertake the myotomy but address the potential future reflux problem. Nevertheless, a number of recent prospective studies demonstrate a continued albeit limited interest in this approach [24, 25].

Laparoscopic Heller Myotomy and Fundoplication. The advent of a minimally invasive abdominal surgery has provided patients a seemingly superior surgical option when compared to either laparotomy or thoracic/thoracoscopic approaches. Laparoscopic surgery is unarguably less invasive, associated with less pain and postoperative disability, and facilitates a shorter hospital stay (usually 1-3 days), making it an attractive surgical alternative in the initial management of patients with achalasia. Furthermore, numerous studies have reported that the laparoscopic approach has a cumulative good to excellent clinical response rate of $94 \%$ with a lower incidence (13\%) of postoperative GERD and no reported mortality (table 4). When studied, the LES pressure is decreased by $59 \%$ (range $42-72 \%$ ) and appeared to correlate with the postoperative symptoms.

Recent experience has confirmed earlier considerations that the laparoscopic approach is superior to the thoracoscopic approach. The thoracoscopic approach is associated with both an increase in persistent dysphagia and a higher prevalence of GERD (table 3). In addition, two recent comprehensive summaries of the thoracoscopic technique by Vaezi and Richter [26] and Shiino et al. [27] respectively reported persistent dysphagia in $>15 \%$ of patients and secondary GERD in 50\%.

Patti et al. [68] and Ramacciato et al. [74] compared the outcome of patients who underwent laparoscopic Heller myotomies and Dor fundoplication to patients who underwent thoracoscopic myotomy without fundoplication (table 5). Dysphagia was completely relieved in $77 \%$ of the laparoscopic and $70 \%$ of the thoracoscopic groups. Patients were more comfortable and left the hospital earlier after laparoscopy (42-48 vs. $84-120$ h). Postoperatively, $31 \%$ of patients in the thoracoscopic group had 24-hour $\mathrm{pH}$ studies consistent with pathologic GERD, compared to only $6 \%$ in the laparoscopic group. These studies further supported the superiority of the laparoscopic approach compared to the thoracoscopic approach for the treatment of achalasia.

\section{Necessity and Type of Antireflux Procedure}

As a result of the surgical cure of achalasia, engendering a different disease-GERD, there has emerged a debate as to whether a prophylactic antireflux procedure might be appropriate. Understandably some degree of controversy exists as to whether an antireflux procedure should be added to the Heller myotomy since the additional operative technique of a fundoplication has its own degree of risk. Furthermore, controversy exists as to the ideal type of fundoplication that should be performed. At 
Table 4. Laparoscopic Heller myotomy ( $n=15$ studies; 1995-2002)

\begin{tabular}{lcccccccc}
\hline Group (first author) & Year & $\mathrm{n}$ & Design & $\begin{array}{l}\text { Antireflux } \\
\text { procedure }\end{array}$ & $\begin{array}{l}\text { \% symptom } \\
\text { improve- } \\
\text { ment }\end{array}$ & $\begin{array}{l}\text { F/U } \\
\text { years }\end{array}$ & $\begin{array}{l}\text { \% compl } \\
\text { GERD }\end{array}$ & $\begin{array}{l}\% \text { compl } \\
\text { mortality }\end{array}$ \\
\hline Rosati [75] & 1995 & 25 & $\mathrm{R}$ & Yes & 96 & 1 & - & 0 \\
Ancona [76] & 1995 & 17 & $\mathrm{R}$ & Yes & 100 & 0.7 & 6 & 0 \\
Morino [77] & 1995 & 18 & $\mathrm{P}$ & Yes & 100 & 0.7 & 6 & 0 \\
Bonovina [78] & 1995 & 33 & $\mathrm{R}$ & Yes & 97 & 1 & - & - \\
Robertson [79] & 1995 & 9 & $\mathrm{R}$ & No & 88 & 1.1 & 13 & 0 \\
Swanstrom [80] & 1995 & 12 & $\mathrm{R}$ & Yes & 100 & 1.3 & 16 & 0 \\
Delgado [81] & 1996 & 12 & $\mathrm{P}$ & Yes & 83 & 0.3 & 0 & 0 \\
Esposito [82] & 1997 & 8 & $\mathrm{R}$ & Yes & 100 & 0.9 & - & 0 \\
Anselmino [83] & 1997 & 43 & $\mathrm{P}$ & Yes & 95 & 1 & 6 & 0 \\
Slim [84] & 1997 & 8 & $\mathrm{R}$ & Yes & 100 & 1 & - & 0 \\
Hunter [85] & 1997 & 40 & $\mathrm{R}$ & Yes & 90 & 1 & - & 0 \\
Wang [98] & 1998 & 27 & $\mathrm{R}$ & No & 89 & - & 11 & 0 \\
Patti [68] & 1999 & 133 & $\mathrm{R}$ & No & 93 & - & 17 & 0 \\
Cade [73] & 2000 & 19 & $\mathrm{P}$ & No & 95 & 2 & 37 & 0 \\
Sharp [86] & 2002 & 95 & $\mathrm{R}$ & No & 86 & 1.2 & 14 & 0 \\
\hline Totals & & 499 & & & $94 \pm 6$ & $1 \pm 0.4$ & $13 \pm 10$ & $0 \pm 0$ \\
\hline
\end{tabular}

$\mathrm{P}=$ Prospective $; \mathrm{R}=$ retrospective $; \mathrm{F} / \mathrm{U}=$ follow-up compl = complications; mean $\pm \mathrm{SDEV}$.

this time there exists no robust data to provide a definitive answer since there are no randomized prospective data available on either topic. In general, surgeons have concluded that inadequate division of the muscle wall results in postoperative dysphagia, while an excessively long myotomy ( $>2 \mathrm{~cm}$ beyond the GE junction) may result in GERD [27]. The proponents of not performing a fundoplication argue that the surgeon can achieve an adequate cardiomyotomy without causing reflux, and that adding an antireflux procedure causes resistance to the flow of food, thereby reducing the effectiveness of the myotomy. Additionally, they point out that the antireflux procedure increases the operative time of the procedure and carries its own additional inherent risks. On the contrary, however, Oelschlager et al. [96] have demonstrated (in a retrospective study) that increasing the gastric myotomy $(>3 \mathrm{~cm})$ more effectively disrupted the LES with a resultant improvement in dysphagia. However, the addition of a Toupet fundoplication was necessary to decrease abnormal reflux patterns and minimize GERD. Although the precise extent of the disadvantage posed by the addition of 90 min additional procedure (a Dor is much less time-consuming) to an operative technique that manages a disease that might otherwise be lifelong, such advocates appear fixated upon this position and propose as an alternative lifelong acid-suppressive thera-
Table 5. Comparison of laparoscopic and thoracoscopic Heller myotomy

\begin{tabular}{lcc}
\hline Result & Thorascopic & Laparoscopic \\
\hline Excellent, \% & 70 & 77 \\
Good, \% & 17 & 13 \\
OR time, min & $150 \pm 16$ & $166 \pm 10$ \\
Length of hospital stay, h & $84-120$ & $42-48$ \\
Abnormal 24-hour pH study, \% & 60 & 10 \\
No dysphagia, \% & 62 & 94 \\
Heartburn, \% & 31 & 6
\end{tabular}

Adapted from Patti et al. J Gastrointest Surg 1998;2:561-566 and Ramacciato et al. Surg Endosc 2002;16:1431-1437.

py to manage the GERD that may emerge as a result of the myotomy.

In 2002, Sharp et al. [86] retrospectively reviewed 95 consecutive patients who underwent a laparoscopic Heller myotomy without an antireflux procedure. Thirty-one of the 95 patients underwent 24-hour $\mathrm{pH}$ monitoring and all patients answered postoperative questionnaires (Gastrointestinal Symptom Rating Scale or GERD-specific Quality of Life in Reflux and Dyspepsia). Mean follow-up was 10 months. Postoperative heartburn was reported in 
Table 6. Results for laparoscopic Heller-Dor ( $\mathrm{n}=12$ studies; 19952003)

\begin{tabular}{lrrrcc}
\hline Group (first author) & Year & $\mathrm{n}$ & Design & $\begin{array}{l}\text { Excellent/ } \\
\text { good out- } \\
\text { come, \% }\end{array}$ & $\begin{array}{l}\text { Dys- } \\
\text { phagia } \\
\%\end{array}$ \\
\hline Rosati [87] & 1995 & 61 & $\mathrm{R}$ & 88 & 10 \\
Anselmino [83] & 1997 & 43 & $\mathrm{R}$ & 88 & - \\
Tatum [88] & 1999 & 20 & $\mathrm{R}$ & 90 & 10 \\
Radovanovic [89] & 2000 & 27 & $\mathrm{R}$ & 100 & 0 \\
Yamamura [90] & 2000 & 24 & $\mathrm{R}$ & 95 & 11 \\
Zaninotto [91] & 2001 & 142 & $\mathrm{R}$ & 90 & 10.6 \\
Pechlivanides [92] & 2001 & 29 & $\mathrm{P}$ & 90 & 10 \\
Patti [93] & 2001 & 102 & $\mathrm{R}$ & 94 & 6 \\
Lai [94] & 2002 & 10 & $\mathrm{R}$ & 90 & - \\
Perretta [95] & 2003 & 63 & $\mathrm{R}$ & 95 & \\
Oelschlager [96] & 2003 & 52 & $\mathrm{R}$ & - & 17 \\
Fernandez [97] & 2003 & 95 & $\mathrm{R}$ & 94 & - \\
\hline Totals & & 668 & & $92 \pm 4$ & $9 \pm 5$ \\
\hline
\end{tabular}

$14 \%$ of the 31 patients, and dysphagia in another $14 \%$. Unfortunately, one supposed advantage of not performing a concomitant fundoplication is to decrease the incidence of postoperative dysphagia. There are few series in the literature with postoperative dysphagia rates greater than $14 \%$. With respect to postoperative GERD, the method by which patients were chosen for 24-hour $\mathrm{pH}$ study was not addressed (only one third of patients were evaluated), so the reported 14\% incidence of GERD is likely under appreciated.

Hunter et al. [85] retrospectively reviewed the outcomes of 40 patients who underwent a laparoscopic Heller myotomy with or without fundoplication (32 Toupet, 7 Dor, and 1 no fundoplication). Dysphagia was eliminated in $90 \%$ of patients, regurgitation in $95 \%$, and heartburn in $81 \%$ of patients. This study was unable to show any symptomatic reflux difference between the patients who underwent either the Dor or Toupet fundoplication. Decker et al. [28] retrospectively reviewed the results of 67 patients who underwent laparoscopic Heller myotomy with Toupet fundoplication. The mean follow-up in these patients was 31 months. Dysphagia was palliated in $83 \%$ of patients, significant regurgitation occurred in $13 \%$ and heartburn was reported in $11 \%$ of patients.

The results of laparoscopic Heller myotomy with a Dor fundoplication are summarized in table $6.92 \%$ of patients reported a good/excellent outcome and 9\% complained of dysphagia. In 2002, Balaji and Peters [29] reported a multi-institutional comparison of the different fundoplication techniques, demonstrating that the Dor anterior fundoplication was associated with less heartburn $(24$ vs. $42 \%, p<0.05)$ and a decreased prevalence of persistent dysphagia ( 4 vs. $22 \%, p<0.05$ ). It has been claimed that the reason for these differences are probably because the Dor procedure leaves the posterior anatomy intact.

\section{Conclusion}

Minimally invasive surgery has expanded to many frontiers over the last 10 years and the current treatment of foregut motility disorders, such as achalasia, provides an excellent example. Based upon current evidence, laparoscopic Heller myotomy is generally accepted as the operative procedure of choice for achalasia. However, controversy exists as to whether a concomitant antireflux procedure is necessary, and if so, what type should be performed. Unfortunately, there are currently no prospective randomized trials that resolve the above questions, but some inferences can be derived from the data currently available.

Given the concern of postoperative reflux as well as the relative ease of adding an antireflux procedure, it seems prudent and reasonable to propose that all laparoscopic Heller myotomies should be accompanied by an antireflux procedure. The anterior (Dor) fundoplication and the posterior (Toupet) fundoplication are the two most commonly employed antireflux procedures used in conjunction with a laparoscopic Heller myotomy. Proponents of the Toupet procedure argue that it prevents the reapproximation of the myotomy and may be better than an anterior fundoplication in preventing postoperative GERD. On the other hand, advocates of the anterior fundoplication procedure argue that it is easy to perform, does prevent reapproximation of the myotomy, protects the anterior esophagus following myotomy and leaves the posterior anatomy intact. Additionally, it has been suggested that adding a Toupet procedure may increase the incidence of postoperative reflux, secondary to retroesophageal dissection, and increase the likelihood of postoperative dysphagia due to angulation of the posterior esophagus. Given the relative merits of the various arguments and the absence of any rigorous data supporting the Toupet procedure, it is our opinion that the anterior (Dor) fundoplication should be regarded as the concomitant antireflux procedure of choice in bolstering a Heller myotomy undertaken for achalasia. Future results of prospective, randomized studies should, however, settle this controversy. 


\section{References}

1 Willis T: Pharmaceutice rationalis sive diatribe de medicamentorum operationibus in humano corpore. London, Hagae Comitis, 1674.

2 Hurst AF: The treatment of achalasia of the cardia: so-called 'cardiospasm.' Lancet 1927;i: 618 .

3 Howard PJ, Maher L, Pryde A, Cameron EWJ, Heading RC: Five-year prospective study of the incidence, clinical features, and diagnosis of achalasia in Edinburgh. Gut 1992;33:10111015.

4 Wong RK, Maydonovitch CL, Metz SJ, Baker JR: Significant DQw1 association in achalasia. Dig Dis Sci 1989;34:349-352.

5 Pinotti HW, Felix VN, Zilberstein B, et al: Surgical complications of Chagas' disease: Megaesophagus, achalasia of the pylorus, and cholelithiasis. World J Surg 1991;15:198-204.

6 Proctor DD, Fraser JL, Mangano MM, Calkins DR, Rosenberg SJ: Small cell carcinoma of the esophagus in a patient with longstanding primary achalasia. Am J Gastroenterol 1992;87: 664-667.

7 Low VH, O'Connor JB: The corrugated esophagus, a sign of severe reflux disease: Radiographic and endoscopic appearance. Dig Surg 2001;18:371-375.

8 Van Dam J: Endosonographic evaluation of the patient with achalasia. Endoscopy 1998; 30(suppl 1):A48-A50.

9 Zeigler K: Endoscopic appearance of the esophagus in achalasia. Endoscopy 1990;22:1-6.

10 Koshy SS, Nostrant TT: Pathophysiology and endoscopic/balloon treatment of esophageal motility disorders. Surg Clin N Am 1997;77 971-991.

11 Hoogewerf WA, Parischa PJ: Pharmacologic therapy in treating achalasia. Gastrointest Endosc Clin N Am 2001;11:311-324.

12 Coccia G, Bortolotti M, Michetti P, Dodero M Prospective clinical and manometric study comparing pneumatic dilation and sublingual nifedipine in the treatment of oesophageal achalasia. Gut 1991;32:604-606.

13 Richter JE: Motility disorders of the esophagus; in Yamada T (ed): Textbook of Gastroenterology. New York, Lippincott, 1991, p 1083.

14 Cuilliere C, Ducrotte P, Zerbib F, et al: Achalasia: Outcome of patients treated with intrasphincteric injection of botulinum toxin. Gut 1997;41:87-92.

15 Mikaeli J, Fazel A, Montazeri G, Yaghoobi M, Malekzadeh R: Randomized controlled trial comparing botulinum toxin injection to pneumatic dilatation for the treatment of achalasia Aliment Pharmacol Ther 2001;15:1389-1396.

16 Bansal R, Nostrant TT, Scheiman JM, Koshy S, Barnett JL, Elta GH, Chey WD: Intrasphincteric botulinum toxin versus pneumatic balloon dilation for treatment of primary achalasia. J Clin Gastroenterol 2003;36:209_ 214.

17 Wehrmann T, Jacobi V, Jung M, Lembcke B, Caspary WF: Pneumatic dilation in achalasia with a low compliance balloon: Results of a 5 year prospective evaluation. Gastrointest Endosc 1995;42:31-36.
18 Anselmino M, Perdikis G, Hinder RA, et al: Heller myotomy is superior to dilatation for the treatment of early achalasia. Arch Surg 1997; 132:233-240.

19 Eckard VF, Aignherr C, Bernhard G: Predictors of outcome in patients with achalasia treated by pneumatic dilation. Gastroenterology 1992;103:1732-1738.

20 Parkman HP, Reynolds JC, Ouyang A, Rosato EF, Eisenberg JM, Cohen S: Pneumatic dilatation or esophagomyotomy treatment for idiopathic achalasia: Clinical outcomes and cost analysis. Dig Dis Sci 1993;38:75-85.

21 Heller E: Extramucöse Cardioplastie beim chronischen Cardiospasmus mit Dilatation des Oesophagus. Mitt Grengeb Med Chir 1913;2: 141-149.

22 De Brune Groenveldt JR: Over cardiosphasmus. Ned Tijdschr Geneeskd1918;54:12811282.

23 Zaaijer JH: Cardiospasm in the aged. Ann Surg 1923;77:615-617.

24 Codispoti M, Soon SY, Pugh G, Walker WS: Clinical results of thoracoscopic Heller's myotomy in the treatment of achalasia. Eur J Cardiothorac Surg 2003;24:620-624.

25 Lee JM, Wang CH, Huang PM, Hsu HH, Chen JS, Lee CJ, Lee YC: Enduring effects of thoracoscopic Heller myotomy for treating achalasia. World J Surg 2004;28:55-58.

26 Vaezi MF, Richter JE: Current therapies for achalasia. Comparison and efficacy. J Clin Gastroenterol 1998;27:21-35.

27 Shiino Y, Filip CJ, Awad ZT, Tomonaga T, Marsh RE: Surgery for achalasia: 1998. J Gastrointest Surg 1999;3:447-455.

28 Decker G, Borie F, Bouamrirene D, Veyrac M, Gullione F, Fingerhut A, Millat B: Gastrointestinal quality of life before and after laparoscopic Heller myotomy with partial posterior fundoplication. Ann Surg 2002;236:750-758.

29 Balaji NS, Peters JH: Minimally invasive surgery for esophageal motility disorders. Surg Clin N Am 2002;82:763-782.

30 Csendes A, Larrain A, Strauszner R, Ayala M: Long-term clinical, radiographic and manometric follow-up of patients with achalasia of the esophagus treated with esophagomyotomy. Digestion 1975;13:27-32.

31 Black J, Vorbach AN, Collis JL: Results of Heller's operation for achalasia of the oesophagus. The importance of hiatal repair. Br J Surg 1976;63:949-953.

32 Kessler B, Stegemann B, Langhans P, Schwering $\mathrm{H}$ : Chirurgische Therapie der Achalasie zur Vermeidung einer Reflux Osophagitis. Helv Chir Acta 1980;47:533-536.

33 Veiga-Fernandes F, Pinheiro MF, Didia G: Cardiomyotomy associated with antireflux surgery in the treatment of achalasia. World J Surg 1981;5:697-702.

34 Csendes A, Braghetto I, Mascaro J, Henriquez A: Late subjective and objective evaluation of the results of esophagomyotomy in 100 patients with achalasia of the esophagus. Surgery 1988;104:469-475.
35 Gonzalez EM, Alvarez AG, Garcia IL, Gutierrez MG, Selas PR, Garcia IG, Navalon JMJ, Diaz JA: Results of surgical treatment of esophageal achalasia. Multicenter retrospective study of 1,856 cases. Int Surg 1988;73:69-77.

36 Sauer L, Pellegrini CA, Way LW: The treatment of achalasia. Arch Surg 1989;124:929932.

37 Isolauri J, Feussner H, Holscher AH, Seiwart JR: Pneumatic dilation and cardiomyotomy with modified Thal fundoplasty in the treatment of achalasia of the esophagus; in Little AG, Ferguson MK, Skinner DB (eds): Diseases of the Esophagus, vol 2: Benign Diseases. Mt Kisco/NY, Futura, 1990, p 299.

38 Makela J, Kiviniemi H, Laitinen S: Heller's cardiomyotomy compared with the pneumatic dilation for the treatment of esophageal achalasia. Eur J Surg 1991;157:411-414.

39 Jaakkola A, Ovaska J, Isolauri J: Esophagocardiomyotomy for achalasia: Long-term clinical and endoscopic evaluation of transabdominal vs. transthoracic approach. Eur J Surg 1991; 157:407-410

40 Bonavina L, Nosadini A, Bardini R, Baessato M, Peracchia A: Primary treatment of esophageal achalasia: Long-term results of myotomy and Dor fundoplication. Arch Surg 1992;127: 222-227.

41 Picciocchi A, Cardillo G, D’Ugo D, Castrucci G, Mascellari L, Granone P: Surgical treatment of achalasia: A retrospective comparative study. Jpn J Surg 1993;23:855-859.

42 Kumar A, Wig JD, Kochhar R, Gupta NM, Nagi B: An audit of pneumatic dilatation and oesophagomyotomy in patients with achalasia cardia. Trop Gastroenterol 1994;15:152-156.

43 Mattioli S, Di Simone M, P, Bassi F, et al: Surgery for esophageal achalasia. Long-term results with three different techniques. Hepatogastroenterology 1996;43:492-500.

44 Pandolfo N, Bortolotti M, Spigno L, Bozzano PL, Mattioli FP: Manometric assessment of Heller-Dor operation for esophageal achalasia. Hepatogastroenterology 1996;43:160-166.

45 Del Genio A, Izzo G, Di Martino N, Maffetone V, Landolfi V, Martella A, Barbato D: Intraoperative esophageal manometry: Our experience. Dis Esophagus 1997;10:253-261.

46 Jordan PH: Long-term results of esophageal myotomy for achalasia. J Am Coll Surg 2001; 193:137-145.

47 Junginger T, Kneist W, Sultanov F, Eckardt VF: Long-term outcome of myotomy and semifundoplication in achalasia. Chirurg 2002;73: 704-709.

48 Mansour KA, Symbas PN, Jones EL: A combined surgical approach in the management of achalasia of the esophagus. Am Surg 1976;42: 192.

49 Okike N, Payne WS, Neufeld DM, Bernatz PE, Pairolero PC, Sanderson DR: Esophagomyotomy versus forceful dilation for achalasia of the esophagus: Results in 899 patients. Ann Thorac Surg 1979;28:119-125. 
50 Jara FM, Toledo-Pereyra LH, Lewis JW, Magilligan J: Long-term results of esophagomyotomy for achalasia of esophagus. Arch Surg 1979; 114:935-936.

51 Bjork S, Dernevik L, Gatinsky P, Sandberg N: Oesophagocardiomyotomy and antireflux procedures. Acta Chir Scand 1982;148:525-529.

52 Ellis FH, Crozier RE, Watkins E: Operation for esophageal achalasia: Results of esophagomyotomy without an anti-reflux operation. J Thorac Cardiovasc Surg 1984;88:344.

53 Murray GF, Buttaglini JW, Keugy BA: Selective application of fundoplication in achalasia. Ann Thorac Surg 1984;37:185.

54 Pai GP, Ellison RG, Rubin JW: Two decades of experience with modified Heller's myotomy for achalasia. Ann Thorac Surg 1984;38:201.

55 Goulbourne IA, Walbaum PR: Long-term results of Heller's operation for achalasia. J R Coll Surg Edinb 1985;30:101.

56 Little AG, Soriano A, Ferguson MK: Surgical treatment of achalasia: Results with esophagomyotomy and Belsey repair. Ann Thorac Surg 1988;45:489-494

57 Stipa S, Fegiz G, Iascone C: Heller-Belsey and Heller-Nissen operations for achalasia of the esophagus. Surg Gynecol Obstet 1990;170: 212-216.

58 Shoenut JP, Wieler JA, Mieflikier AB, Teskey JM: Esophageal reflux before and after isolated myotomy for achalasia. Surgery 1990;108:876879.

59 Ellis FH: Oesophagomyotomy for achalasia: A 22-year experience. Br J Surg 1993;80:882885

60 Abid S, Champion G, Richter JE, McElvin R, Slaughter RL, Koehler RE: Treatment of achalasia: The best of both worlds. Am J Gastroenterol 1994;89:979-985.

61 Malthaner RA, Todd TR, Miller L, Pearson FG: Long-term results in surgically managed esophageal achalasia. Ann Thorac Surg 1994; 58:1343-1347.

62 Ferguson MK, Reeder LB, Olak J: Results of myotomy and partial fundoplication after pneumatic dilation for achalasia. Ann Thorac Surg 1996;62:327-330.

63 Maher JW: Thoracoscopic esophagomyotomy for achalasia: Maximum gain, minimum pain Surgery 1997;122:836-840.

64 Shai SE, Chen CY, Hsu CP, Hsia JY, Yang SS Transthoracic oesophagectomy in the treatment of achalasia: A 15-year experience. Scand Cardiovasc J 1999;33:333-336.

65 Rea S, Kelly CJ, Broe PJ: Thoracoscopic Heller's myotomy for oesophageal achalasia. Ir J Med Sci 1999;168:10-12.

66 Jordan PH: Long-term results of esophageal myotomy for achalasia. J Am Coll Surg 2001; 193:137-145

67 Pellegrini CA, Leichter R, Patti M, Somberg K, Ostroff JW, Way L: Thoracoscopic esophageal myotomy in the treatment of achalasia. Ann Thorac Surg 1993;56:680-682.
68 Patti MG, Pellegrini CA, Arcerito M, Tong J, Mulvihill SJ, Way LW: Comparison of medical and minimally invasive surgical therapy for primary esophageal motility disorder. Arch Surg 1995;130:609-616.

69 Cade RJ, Martin CJ: Thoracoscopic cardiomyotomy for achalasia. Aust NZ J Surg 1996; 66:107-109.

70 Raiser F, Perdikis G, Hinder RA, Swanstorm LL, Fillipi CJ, McBride PJ, Katada N, Neary PJ: Heller myotomy via minimal access surgery: An evaluation of anti-reflux procedures. Arch Surg 1996;131:593-598

71 Nguyen NT, Schauer PR, Hutson W, Landreneau R, Weigel T, Ferson PF, Keenan RJ, Luketich JD: Preliminary results of thoracoscopic Belsey Mark IV antireflux procedure. Surg Laparoscop Endosc 1998;8:185-188.

72 Patti MG, Pelligrini CA, Horgan S, Arcerito M, Omelanczuk P, Tamburini A, Diener U, Eubanks TR, Way LW: Minimally invasive surgery for achalasia: An 8-year experience with 168 patients. Ann Surg 1999;230:587-593.

73 Cade R: Heller's myotomy: Thoracoscopic or laparoscopic? Dis Esophagus 2000;13:279281.

74 Ramacciato G, Mercatini P, Amodio PM, Stipa F, Carogliano N, Ziparo V: Minimally invasive surgical treatment of esophageal achalasia. J Soc Laparoendosc Surg 2003;7:219-225.

75 Rosati R, Fumagalli U, Bonavina L, et al: Laparoscopic approach to esophageal achalasia. Am J Surg 1995;169:424-427.

76 Ancona E, Anselmino M, Zaninotto G, Costantini M, Rossi M, Bonavina L, Boccu C, Buin F, Peracchia A: Esophageal achalasia: Laparoscopic versus conventional open Heller-Dor operation. Am J Surg 1995; 170:265-270.

77 Morino M, Rebecchi F, Festa V, Garrone C: Laparoscopic Heller cardiomyotomy with intraoperative manometry in the management of oesophageal achalasia. Int Surg 1995;80:332335.

78 Bonovina L, Rosati R, Segalin A, Peracchia A: Laparoscopic Heller-Dor operation for the treatment of oesophageal achalasia: Technique and early results. Ann Chir Gynaecol 1995;84: 165-168.

79 Robertson GSM, Lloyd DM, Wicks ACB, DeCaestecker J, Veitch PS: Laparoscopic Heller's cardiomyotomy without an anti-reflux procedure. Br J Surg 1995;82:957-959.

80 Swanstrom LL, Pennings J: Laparoscopic esophagomyotomy for achalasia. Surg Endosc 1995;9:286-292.

81 Delgado F, Bolufer JM, Martinez-Abad M, et al: Laparoscopic treatment of esophageal achalasia. Surg Lap Endosc 1996;2:83-90.

82 Esposito PS, Sosa JL, Sleeman D, Santelices AA: Laparoscopic management of achalasia. Am Surg 1997;63:221-223.

83 Anselmino M, Zaninotto G, Costantini M, Rossi M, Bocca C, Ancona E: One-year followup after laparoscopic Heller-Dor operation for esophageal achalasia. Surg Endosc 1997;11:3-
84 Slim K, Pezet D, Chipponi J, Boulant J, Mathieu S: Laparoscopic myotomy for primary esophageal achalasia: Prospective evaluation. Hepatogastroenterology 1997;44:11-15.

85 Hunter JG, Trus TL, Branum GD, Waring JP: Laparoscopic Heller myotomy and fundoplication for achalasia. Ann Surg 1997;225:655665.

86 Sharp KW, Khaitan L, Scholz S, Holzman MD, Richards WO: 100 consecutive minimally invasive Heller myotomies: Lessons learned. Ann Surg 2002;235:631-639.

87 Rosati R, Fumagalli U, Bona S, Bonavina L, Pagani M, Peracchia A: Evaluating results of laparoscopic surgery for esophageal achalasia. Surg Endosc 1998;12:270-273.

88 Tatum RP, Kahrilas PJ, Manka M, Joehl RJ: Operative manometry and endoscopy during laparoscopic Heller myotomy. An initial experience. Surg Endosc 1999; 13:1015-1020.

89 Radovanovic N, Feussner H, Stein H, Siewert JR: Laparoscopic cardiomyotomy in the treatment of esophageal achalasia. Acta Chir Iugos 2000;47:75-79.

90 Yamamura MS, Gilster JC, Myers BS, Deveney CW, Sheppard BC: Laparoscopic Heller myotomy and anterior fundoplication for achalasia results in a high degree of patient satisfaction. Arch Surg 2000;135:902-906.

91 Zaninotto G, Constantini M, Molena D, Portale G, Constantino M, Nicoletti L, Ancona E: Minimally invasive surgery for esophageal achalasia. J Laparoendosc Adv Surg Tech A 2001;11:351-359.

92 Pechlivanides G, Chrysos E, Athanasakis E, Tsiaoussis J, Vassilakis JS, Xynos E: Laparoscopic Heller cardiomyotomy and Dor fundoplication for esophageal achalasia: Possible factors predicting outcome. Arch Surg 2001;136: 1240-1243

93 Patti MG, Molena D, Fisichella PM, Whang K, Yamada H, Perretta S, Way LW: Laparoscopic Heller myotomy and Dor fundoplication for achalasia: Analysis of successes and failures. Arch Surg 2001;136:870-877.

94 Lai IR, Lee WJ, Huang MT: Laparoscopic Heller myotomy with fundoplication for achalasia. J Formos Med Assoc 2002;101:332-336.

95 Perretta S, Fisichella PM, Galvani C, Gorodner MV, Way LW, Patti M: Achalasia and chest pain: Effect of laparoscopic Heller myotomy. J Gastrointest Surg 2003; 7:595-598.

96 Oelschlager BK, Chang L, Pellegrini CA: Improved outcome after extended gastric myotomy for achalasia. Arch Surg 2003;138:490 495.

97 Fernandez AF, Martinez MA, Ruiz J, Torres R, Faife B, Torres JR, Escoto CM: Six years of experience in laparoscopic surgery or esophageal achalasia. Surg Endosc 2003;17:153-156.

98 Wang PC, Sharp KW, Holzman MD, Clemens RH, Holcomb GW, Richards WO: The outcome of laparoscopic Heller myotomy without antireflux procedure in patients with achalasia. Am Surg 1998;64:515-520. 